\title{
The games psychologists play (and the data they provide)
}

\author{
DAVID A. WASHBURN \\ Georgia State University, Atlanta, Georgia
}

\begin{abstract}
Computer games and the technologies marketed to support them provide unique resources for psychological research. In contrast to the sterility, simplicity, and artificiality that characterizes many cognitive tests, game-like tasks can be complex, ecologically valid, and even fun. In the present paper, the history of psychological research with video games is reviewed, and several thematic benefits of this paradigm are identified. These benefits, as well as the possible pitfalls of research with computer game technology and game-like tasks, are illustrated with data from comparative and cognitive investigations.
\end{abstract}

Preparing this presidential address, I was reminded of the day in 1982 when I purchased my first computer. With a few hundred dollars in my pocket and the chairman of the computer science department at my side (to ensure that I made a wise purchase of a serious computer), I researched my limited options and bought a Commodore VIC-20. The VIC-20 was marketed as the first full-color computer for under $\$ 300$, although I seldom benefitted from the 16 colors it could produce, because I always connected it to my 9-in. black-and-white television. With its $1.01 \mathrm{MHz}$ processor, $3.5 \mathrm{~K}$ of RAM, and $16 \mathrm{~K}$ of ROM (that's kilobytes, not gigabytes or even megabytes!), the computing power of the VIC-20 is dwarfed by many of today's toys and calculators. However, it was indeed a real computing machine of its day, for which one could purchase a variety of software for entertainment, education, and business. ${ }^{1}$ Of course, this software had to be burned as a ROM cartridge, typed from scratch into BASIC or machine language, or loaded off of cassette tape, because the VIC-20 had no hard drive, disk drive, or disk operating system.

I left the computer store $\$ 400$ poorer but carrying my computer, a data cassette drive, and one cassette tape of software (a clone of the Pac-man game). My computer science professor, who had endorsed the purchase largely because one could write BASIC programs for the VIC-20, provided me with space to set up the computer and returned a few minutes later to check on my progress. On

The research discussed here was supported by grants from NICHD (HD-38051), NASA (NAG2-1251 and NAG2-438), the Army Research Office and the Army Research Institute, and the College of Arts and Sciences of Georgia State University. The author thanks Duane Rumbaugh, Jonathan Gulledge, William Hopkins, Lauren Baker, Pamela (Raby) Rice, R. Thompson Putney, William Tirre, and Douglas Sizemore for their contributions to this paper. Correspondence concerning this article should be addressed to D. A. Washburn, Department of Psychology, Georgia State University, Atlanta, GA 30303 (e-mail: dwashburn@gsu.edu). his return, he found me with joystick in hand, happily chomping away at little dots on the screen, deeply engrossed in my game. His face showed immediate disappointment, as did his voice, as he chided, "You're not being . . . academic!" Coming as it did from this oldschool professor, a true paragon of the Academy, it was as harsh a rebuke as I have ever received!

In retrospect, one might imagine that I have spent the last two decades examining ways of making computer games, or at least some elements and technologies from the games, more academic. That is, I have been (and remain) interested in the application of computer game methodologies to psychological research. I have certainly not been alone in this fascination, and in the present paper I will review briefly the history and nature of literature on psychological research with computer games and then list some of the disadvantages and advantages that are apparent in this literature. These general principles will be illustrated with data from my own research, although studies by many other investigators could also be used to exemplify the promises and pitfalls of this research paradigm.

\section{History of Psychological Research With Computer Games}

Of course, one could quibble over what does or does not constitute a computer game. Aside from Wittgenstein's (1953) classic debate over the definition of a game, one must also acknowledge that the line between computerbased tasks (e.g., a computerized version of a serial-probe recognition task or the Stroop task) and a computerized game is a blurred one, made even less distinct by the increasing complexity and verisimilitude of computer-based simulations, virtual environments, and so forth. Fundamentally, you know a game when you are playing it, and one person's game (implying fun) might well be another person's task (implying work) or chore (implying tedium). For the present review, I included as relevant any papers in 
which the authors themselves used such terms as computer game, game-like task, video game, or video task.

The first paper referenced by PsycInfo in which one of these terms was included in the title or abstract was in 1972, in which a computer simulation of dominoes game performance was described (Reisman, 1972). Two years later, Waksman (1974) published guidelines for programming computer games. The first psychological study in which computer games were mentioned appeared in 1976. Reflecting what would be a theme in many subsequent studies, Arnold (1976) allowed participants to play computer games and tested the effects of performance feedback on motivation. Two years later, Isen, Shalker, Clark, and Karp (1978) examined participants' memory for winning or losing a computer game. That same year, Coombs (1978) speculated on the future of simulation and gaming research, anticipating, in a way, the corpus of studies that would separate his publication and the present review.

Studies on the effects of computer game playing on verbal behavior (Scheibe \& Erwin, 1979) and on physiology (Moulds, 1979) appeared in 1979, ushering in a trend to use off-the-shelf computer games as a source of stimulation for purposes of assessing their effects outside of the game itself. Another major trend in this literature appeared in 1980, with a dissertation on the instructional potential of computer games (Malone, 1980). In 1981, the first of a series of studies was reported by Jones, Kennedy, Bittner, and their colleagues (Jones, Kennedy, \& Bittner, 1981a, 1981b; Kennedy, Bittner, \& Jones, 1981; see also Kennedy, Bittner, Harbeson, \& Jones, 1982), who were interested in the use of computer games for assessment and prediction of subsequent performance (e.g., by Air Force pilots). Thus, by the end of 1981 , only 11 papers in the psychological literature had made explicit mention of computer games (or some similar term). In these few papers, however, the groundwork was already set to use computer games as stimuli for studying other forms of behavior, as vehicles for instating the experimental manipulation of some variable, as tools for education or instruction, and as methods for performance assessment and prediction.

Almost as many citations appear in 1982 as in all of the previous years combined. Mickel (1982) reviewed the innovative use by psychologists of video games to restore and measure mental functions in seriously injured patients. Two dissertations were produced on the strategies employed while video games were played. Four papers were published on instructional applications of computer games, including Lesgold's (1982) study on using computer games to teach reading, which was the first computer game study I could find to appear in the present journal. In addition, Yermakova (1982) published a Russian language article in which a series of programs was described "for conducting psychological experiments in which data may be obtained from subjects' responses in game-like situations" (p. 125). Certainly, this notion of a battery of experiment generation programs has remained popular, as was reviewed in the presidential address of my predecessor (Ransdell, 2002).

The number of citations in the psychological literature in which computer games (or the like) were mentioned continued to climb across the next few years: 10 papers in 1982, 25 papers in 1983, 34 papers in 1984, 37 papers in 1985 , and 45 papers in 1986 . This plateau of about 43 papers per year (range $=36$ papers in 1990 to 48 papers in 1992 and 1993) on psychological research with computer games continued until 1994, when a new plateau was established at around 62 papers per year (range $=55$ papers in 1997 to 70 papers in 1994 and 2001). Not only did the number of papers change across the years, but the distribution of topic within this literature also shifted. This can be seen in the three panels of Figure 1.

In 1983 , merely $28 \%$ of the studies ( 7 of 25 ) used computer games in an experimental way, examining the effects of game playing on other behaviors (e.g., social behavior or readiness to learn) or on physiology (e.g., heart rate). Included in this subtotal is the 1 study in which an experimental manipulation was directly programmed into a game-like task. When the number of computer game publications surged in 1994, over half of the studies were experimental in nature. Studies of the effects of game playing on behavior (16 papers) and on physiology (8 papers) continued to be popular. By 1994, however, it was increasingly common to find reports in which experimental manipulations were programmed as game-like tasks. Note that this increase in experimental studies did not come at a cost to those investigations of computer games as training or assessment tools. Note also that the literature in 1994 contained 1 study of whether aggressive video games result in aggressive extra-game behavior. In the most recent year of the present review, such studies on computer game effects on aggression are as common as those in any other category (Figure 1C).

\section{Problems With Game-Based Research}

This literature reveals several clear drawbacks to conducting research with computer game hardware and software. Chief among these are the programming demands associated with computer games. Although commercial games may invoke a variety of cognitive processes, they do not typically support the collection of data that are useful to psychologists and certainly do not permit the experimenter to have full control over all of the variables that can affect performance. Consequently, game software must be modified or game-like tasks must be written from scratch for the unique purposes of each experimenter. This is a much more substantial investment than would be required to develop a paper-and-pencil test of memory, for instance, or even a relatively simple computerized task (e.g., a serial-probe recognition task).

In addition, games can introduce complexity to the experimental situation that has negative consequences. For example, a driving simulator might provide an interesting and ecologically valid platform for studying vigilance, but it might introduce psychomotor factors, moti- 

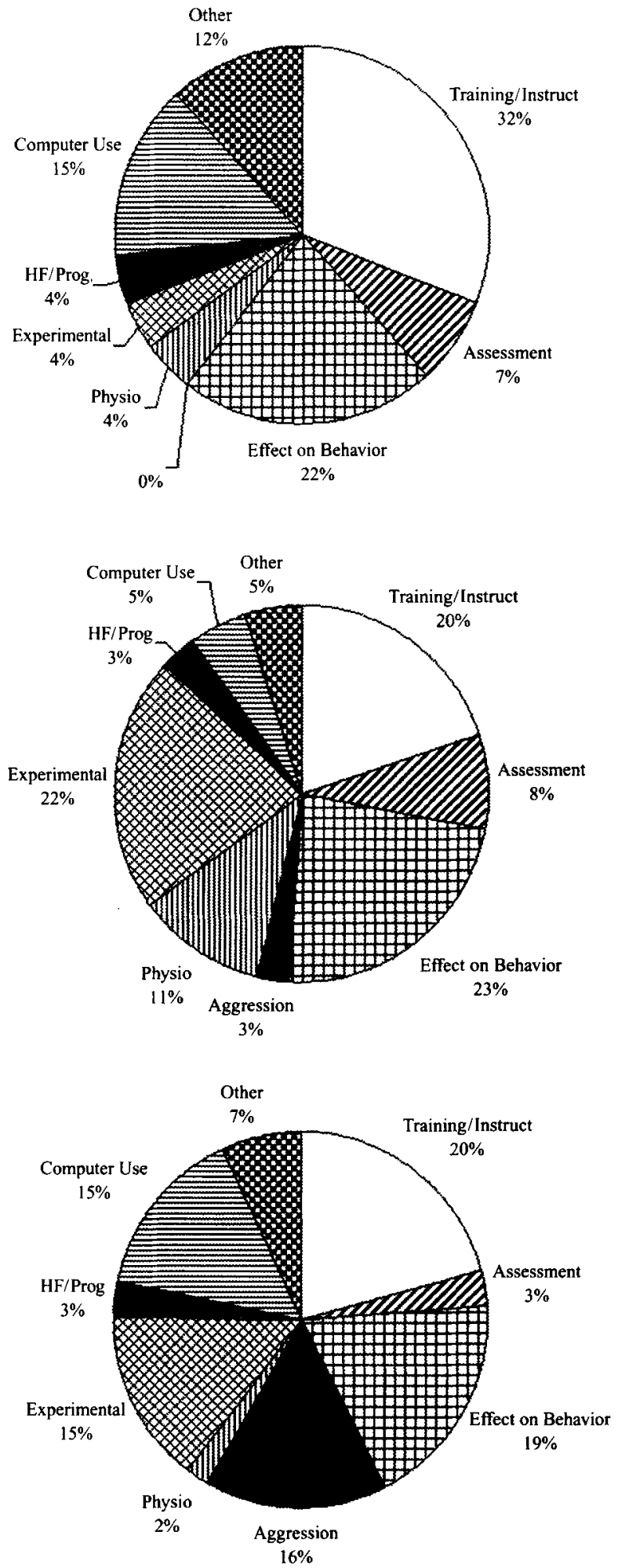

Figure 1. Percentage of PsycInfo citations (including key terms such as computer game, video game, and game-like tasks) by the categories training and instruction, assessment, effects on nonaggressive behavior, effects on aggression, physiological effects, experimental studies, human factors and programming, studies of computer use, and other. These percentages are based on the 25 papers published in 1983 (top), the 70 papers published in 1994 (middle), and the 70 papers published in 2001 (bottom). vational variables, attention-scanning demands, and so forth that obfuscate the variable of interest. After all, this is why laboratory tasks (e.g., a signal detection task in which vigilance decrements are observed in the latency and accuracy of responses to infrequent target stimuli) are used more often than real-world contexts (e.g., performance by sentries or radar operators) in psychological research. Whereas one anticipates that the laboratory tasks will generalize to the real-world situations, the complexity of the latter can make it difficult to conduct research in them directly.

Third, there is a perception problem associated with the use of computer games in psychological research. Because games are designed for entertainment, research with computer games runs the risk of appearing frivolous and less serious than other types of laboratory research. Although this may be no problem if one is interested in studying the effects of computer game playing itself, it is a significant hazard for researchers who want to use game-like tasks and technologies to understand the basic processes that underlie behavior. Indeed, one can imagine a funding agency being criticized (inappropriately) for investing thousands of dollars into research that requires participants to play computer games. Doubtless, this same agency would not be criticized if the same computerized tests were described as tasks rather than as games. For this reason, I have advocated the use of such terms as game-like tasks to describe serious cognitive and comparative research tests that employ the graphics, hardware, competition, or other elements of computer games.

\section{Benefits of Game-Based Research: A Common Platform}

Against these three major categories of detriment, however, several advantages have been revealed in the literature on psychological research with the computer game paradigm. One benefit of conducting psychological research with computer games is that these games provide a standard platform for research across researchers, laboratories, and subdisciplines. Indeed, this was one of the major themes of the first symposium on "Psychological Research With Computer Games" organized for the annual program of the Society for Computers in Psychology in 1994 (e.g., Allan, 1995; Porter, 1995). Several of the speakers who participated in that symposium emphasized the common platform theme. Case (1995) described modifications to a familiar computer game that he used to study operant behavior and that Gonzalez and Cathcart (1995) were also using on the other side of the country to study strategy formation. Similarly, Donchin (1995) reviewed the learning strategies program in which multiple investigators, each at different universities representing several different countries and numerous specific research interests, collaborated on a project using a single common computer game ("Space Fortress;" see Mane \& Donchin, 1989; for recent research using the same game, see, e.g., Arthur et al., 1995; Shebilske, Goettl, Corrington, \& Day, 1999). 
Some researchers were interested in attention, whereas others were interested in learning or memory; however, all were able to conduct their research by using a common experimental platform. The result was an unprecedented opportunity for comparison across psychological processes.

In that same symposium, my colleagues and I described the common platform afforded by game-like tasks for comparative research. That is, computer game hardware and software specially written to instantiate experimental questions as game-like tasks permitted the direct comparison of performance by humans (of various ages and demographic groups) and nonhuman primates (apes and monkeys). This comparative research began when the language-trained chimpanzees Sherman and Austin were permitted to play computer games as part of their environmental enrichment (Savage-Rumbaugh, 1986). Given the success of these efforts, we endeavored to determine whether rhesus monkeys could learn to manipulate a joystick so as to control the movements of a cursor in a battery of computerized game-like tasks. A curriculum of training software was programmed, and the typical computer game hardware of the day (i.e., a computer, a color monitor, a joystick, and an external speaker) was modified to permit the automated delivery of fruit-flavored reinforcers upon completion of trials (see Figure 2). Despite a 50-year literature suggesting that the monkeys would fail to learn such tasks (Rumbaugh, Richardson, Washburn, Savage-Rumbaugh, \& Hopkins, 1989), the monkeys did quickly master the tasks. In the years since, the animals have demonstrated the ability to learn and to perform a variety of game-like versions of many of the classic testing paradigms of cognitive, comparative, and developmental psychology and neuropsychology (e.g., Filion, Washburn, \& Gulledge, 1996; Hopkins, Washburn, \& Rumbaugh, 1990; Smith, Shields, Allendoerfer,
\& Washburn, 1998; Washburn, 1993, 1994; Washburn \& Astur, 1998; Washburn, Hopkins, \& Rumbaugh, 1989; Washburn \& Rumbaugh, 1991a, 1991b).

Moreover, many simple, familiar games have been used with humans and nonhuman primates (e.g., Washburn \& Gulledge, 1995, in press). Not only does this mean that humans, apes, and monkeys could be tested with identical software and hardware under comparable conditions, but it also means that the tasks themselves are known and understood by researchers. So, for example, I can describe our efforts to teach monkeys to play tic-tac-toe as a means to study monkeys' capacity for learning simple strategies, and the reader will immediately understand the nature of the game and the strategies that lead to good performance (and will recall, perhaps, previous reports in which animals played tic-tac-toe either in the service of science or as entertainment; e.g., Breland \& Breland, 1961; Hanley, Walter, \& Rhodes, 1968). Two monkeys did indeed learn to place Xs into a tic-tac-toe grid and won many games against the computer when the computer responded by chance alone. As the computer was allowed to be increasingly skillful in its play of the game (i.e., when the positioning of the Os was made nonrandom), the number of games won by the monkeys dropped precipitously (see Figure 3). Of particular note, the monkeys tended to respond in a very stereotyped way (e.g., always trying to put three Xs in the first column of the grid) and seldom won when required to deviate from this stimulus-response associative pattern. Furthermore, the monkeys were not observed to use a blocking strategy (i.e., to put an $\mathrm{X}$ in a position that would prevent the computer from having three Os in a row). Thus, we concluded that the monkeys did not develop the simple strategies that characterize even children's skillful performance of the tic-tac-toe game.

These data illustrate the first benefit of psychological research with computer games. These game-like tasks

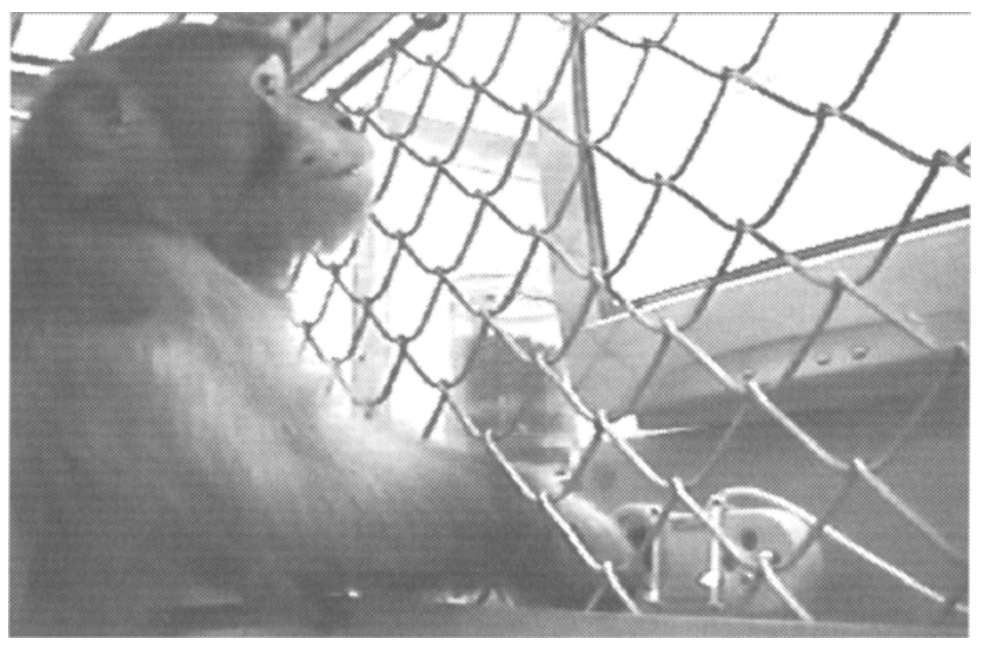

Figure 2. Apparatus used for computer task research with rhesus monkeys. The monkey reaches through the mesh of his home cage to manipulate a joystick, which in turn controls the movements of a cursor on the screen. Pellet rewards are automatically dispensed upon successful completion of each trial. 


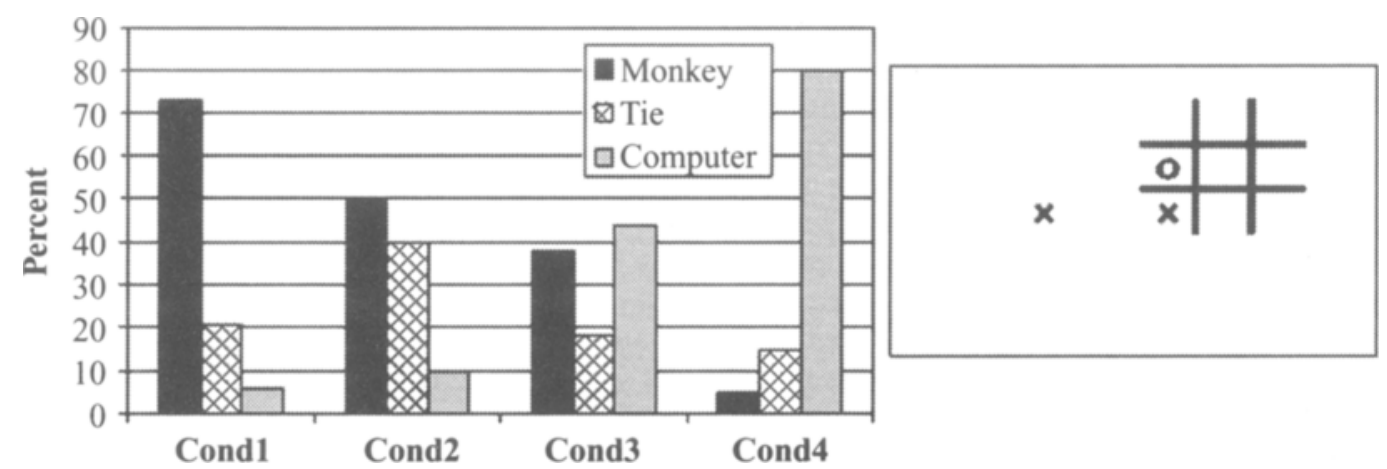

Figure 3. Mean percentage of tic-tac-toe trials won by the monkeys against the computer, as a function of condition. In Condition 1, the monkey always moved first, and the computer selected cells randomly. In Condition 2 , either the computer or the monkey moved first (randomly determined), and the computer selected cells randomly. In Condition 3, either player moved first, and the computer selected cells so as to achieve three in a row. In Condition 4, the computer also blocked wins by the monkeys. The inset shows how the task looked on the computer screen.

and apparatus provide a shared and familiar platform for research across investigators, across laboratories, across topics of psychological interest, across participant populations, and even across species.

\section{Benefits of Computer Game Research: More Motivation and Better Performance}

Imagine a continuous performance task (CPT) in which a stream of letters flashes on the screen, one every $2 \mathrm{sec}$, for a 12-min vigil. Most of the presentations are the letter $X$, to which no response must be made; however, $20 \%$ of the trials, randomly determined, involve the presentation of an $\mathrm{H}$ stimulus. When the participant sees an $\mathrm{H}$, he or she is to press the mouse button as quickly as possible. The primary measures of performance are the accuracy (hit, miss, and false alarm rates) and latency of response to the target letters. The participants are instructed to respond as quickly and as accurately as possible.

Now imagine a game modeled loosely after the movie Star Wars. The goal of the game is to detect enemy ships but to ignore any friendly ships that appear on the radar. Ships appear, one at a time, at 2-sec intervals. You may recall that the good guys in Star Wars flew in X-shaped fighters, whereas the bad guys flew in H-shaped fighter ships. Thus, the player is instructed to press the mouse button as quickly as possible whenever an $\mathrm{H}$-shaped ship appears. Points are earned by responding accurately (hitting all of the enemies and avoiding false alarms) and quickly. The game lasts for $12 \mathrm{~min}$.

Obviously, the former task and the latter game are identical, except for the cover story. In each case, the participant has to detect targets, ignore nontargets, and maintain attention for the 12 -min vigil. One would not expect performance to differ between the two versions. However, Table 1 shows the results when 31 undergraduate volunteers were tested on the two versions of the task, 15 students on the CPT version and 16 students on the game version. The participants were very good at de- tecting the target in both versions of the task, but responses were significantly more accurate in the CPT version than in the game version $[t(29)=2.07, p<.05]$. However, responses were about $12 \%$ faster in the game condition than in the task condition, a difference that was highly reliable $[t(29)=2.48, p<.02]$. That is, the pattern of performance was significantly different on the two versions of the task, despite the fact that the software itself was identical between the two cover stories. The speed-accuracy tradeoff that was observed here is characteristic of the effects of competition (Washburn et al., 1989), suggesting that people perform differently when they think they are playing a game, because they are trying to win.

This suggests a second potential advantage to using games for psychological research: They may produce improved performance. One might, conversely, suppose this to be a disadvantage of game-like tasks. Although it is not new to observe that motivation can change cognitive performance, one typically hopes that manipulations as subtle as the cover story told about a task would be inconsequential with respect to task performance. Knowing that individuals differ in the degree to which they find any task to be engaging, challenging, or fun, the present results reveal another degree of freedom that must be accounted for in the explanation and prediction of behavior. Nevertheless, I have included this effect as

Table 1

Results When the Identical Test is Presented to 15 Participants With Task-Like Instructions and to 16 Participants Using Game-Like Instructions

\begin{tabular}{lccccc}
\hline & \multicolumn{2}{c}{$\begin{array}{c}\text { Accuracy } \\
\text { T\%) }\end{array}$} & & \multicolumn{2}{c}{$\begin{array}{c}\text { Response Time } \\
\text { T(msec) }\end{array}$} \\
\cline { 2 - 3 } \cline { 5 - 6 } \multicolumn{1}{c}{} & $M$ & $S D$ & & $M$ & $S D$ \\
\hline Continuous performance task & 99 & 1 & & 609 & 78 \\
Star Wars game & 97 & 3 & & 537 & 84 \\
\hline
\end{tabular}


an advantage of game-like tasks, in that one can get the best performance possible on a cognitive task.

It is most clear that this effect of game-like tasks is a benefit in the arena of instruction and training. Some of the earliest research uses of computer games were as tools for teaching or training, and these applications have remained popular across the decades. Simulators, computerbased drills, and educational games are developed on the principle that one can make learning fun and more efficient by incorporating game-like aspects of movement, interactivity, competition, scorekeeping, and graphics.

In my own research, I had the good fortune of obtaining support from the Army Research Institute and the Army Research Office to study the effects of simple games on learning and performance. Computerized drills were written to teach students a variety of new information. This information was presented either in static displays on the computer screen or in dynamic displays in which stimuli moved and had to be pursued and captured on the screen. For example, in one study, 45 students were trained on the meanings of visuospatial stimuli (lexigrams, used in language intervention with nonspeaking children and in apelanguage research; Romski \& Sevcik, 1996; Rumbaugh, 1977; Savage-Rumbaugh, 1986). Some of the stimuli remained stationary on the screen. Some of the stimuli moved, and the students had to manipulate a joystick so as to bring a cursor into contact with the elusive targets. Similarly, 14 students were trained, in a second study, to recognize the names of fictitious airplanes. Again, some airplanes were presented in a static format, whereas others moved and required the participants to catch them on the screen.

The results of these two experiments were comparable and are summarized in a composite Figure 4. Performance was significantly better in the acquisition portion of the studies. That is, stimuli that moved in a game-like way were learned better than those stimuli that remained stationary on the screen. Moreover, tests of recall for the symbol meanings or airplane names after 7-14 days revealed that those stimuli learned under game-like conditions were remembered better than those stimuli learned without the game.

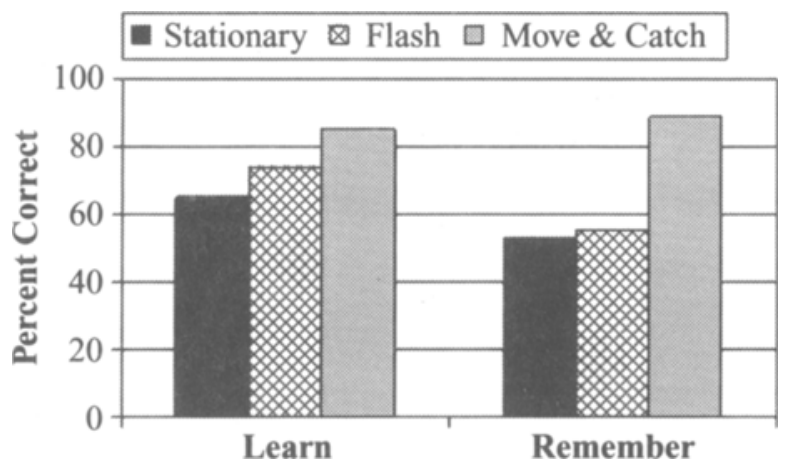

Figure 4. Mean accuracy during training and on subsequent retention tests for stimuli that moved in a game-like way, remained stationary, or (in Experiment 3, on the right) flashed on the screen.
This effect did not simply reflect the perceptual disposition to orient to moving stimuli, since the effect was observed when an orientation response was required to the stationary, as well as the moving, stimuli. In fact, 20 students subsequently learned the Russian equivalent of English words more quickly when the words moved on the screen (and had to be chased and caught) than when they remained stationary or when they flashed--the latter manipulation designed also to capture attention. As can be seen in the right half of Figure 4, both learning and retention (tested 14-28 days after training) were significantly better for words that moved during training than for those that remained stationary or that flashed. Again, the game-like conditions promoted efficient and effective training of these undergraduate students, an effect that has been replicated with nonhuman primates (Washburn, 1993), with college students learning classroom-relevant information (Washburn, Putney, \& Henderson, 1995), and with adults from a temporary employment agency learning job skills (Washburn \& Raby, 2003).

\section{Benefits of Computer Game Research: \\ Enjoyment and Well-Being}

And why do game-like conditions result in higher accuracy, faster responding, efficient learning, and improved retention? The effects of game-like conditions on motivation, attention, and strategy remain poorly understood. However, it also seems likely that performance is altered as a function of psychological well-being and that game-playing would be expected to result in benefits to psychological well-being.

Games are supposed to be fun. If there is a defining characteristic of games, it is that they are enjoyable. Thus, the third benefit of conducting psychological research with computer games is that they may be more enjoyable for the participants than are more traditional tests. Volunteers may enjoy their participation in psychology experiments more if tests can be made more game-like. Games may make it possible to conduct research with children, with the aged, and with institutionalized populations, providing access to key psychological data while simultaneously improving their psychological fitness and happiness.

This possibility is illustrated by research with nonhuman primates. There are ethical and scientific reasons to ensure the psychological, as well as the physical, wellbeing of all laboratory animals maintained for research. In addition, legal motivation is provided by the Animal Welfare Act, amended in 1985 to require researchers to provide an environment that ensures the psychological well-being of nonhuman primates. We have reported the results of numerous studies that demonstrate that the game-like computer tasks we developed for research with monkeys and apes allow us to obtain data on comparative cognition while concomitantly enriching the animals' environments.

How can one determine whether a monkey enjoys a computer task and whether the task improves psychological well-being? First, we examined each animal's preference for engaging the joystick tasks relative to other favored activities. We found that playing the spe- 
cially designed computer games is a highly preferred activity for the nonhuman primates, occupying a substantial portion-over $9 \mathrm{~h}$ per day, on average - of each animal's daily time budget (Washburn \& Rumbaugh, 1992). The monkeys choose to engage in the tasks even when other attractive manipulanda and activities are available. The activities that get replaced in the daily repertoire are predominantly maladaptive and stress- or boredom-related behaviors, such as stereotypy, overgrooming, and aggression. That is, the behavioral indications of psychological distress are significantly reduced when the animals have access to the computer task hardware and software. Indeed, Figure 5 reveals that no intervention has as potent an effect on rhesus monkeys' psychological well-being as does the computerized test system. Although one can reduce the symptoms of depression, boredom, and stress with other forms of environmental enrichment (e.g., social housing, other toys, or manipulanda), the joystickbased apparatus and game-like tasks have a substantial effect over and above these other manipulations.

One might assume that the monkeys' affinity for the computerized tasks is driven by the fact that performance is reinforced with food. However, it bears emphasis that the monkeys and apes are not deprived of food or reduced in body weight for purposes of testing. That is, the animals are fully provisioned whether or not they work. Generally, the monkeys have continuous access to the joystick, computer screen, and tasks. They work when they want to work, rest when they want to rest, and frequently have menu-driven choice over what task they perform at any time. Thus, the animals need not engage in the computer tasks in order to obtain food.

Furthermore, they will continue to work on the tasks even when pellets are made freely available. Washburn and Rumbaugh (1992) reported one experiment in which the monkeys were given free and continuous access to an unlimited supply of fruit-flavored pellets. Under these conditions, the animals spend most of their time eating and sleeping; however, they continue to manipulate the joystick and to complete trials, albeit at relatively reduced levels, even when the pellets are no longer consumed. In a second experiment, the monkeys were given a choice between receiving pellets freely or working on computer tasks for pellets. When the free-food option yielded 30 min of pellets, dispensed automatically, but the joystick tasks were made unavailable for that period, the monkeys were reliably unlikely to select this option. That is, they opted to work for pellets rather than receiving them freely, but only when receiving them freely meant that the joystick tasks would be withheld for a period of time. Although we may not know what makes the game-like tasks enjoyable to the monkeys, it seems clear that food alone is not the reason.

Of course, joystick-based computer games are unlike anything that a rhesus monkey would naturally encounter in its ecological niche. Rather than supporting psychological well-being by making the laboratory more like the wild, we have chosen to employ this highly unnatural technology to address the basic factors of psychological well-being: comfort, companionship, challenge, and control (Washburn \& Rumbaugh, 1992).

\section{Benefits of Computer Game Research: New Opportunities for Science}

But in some cases, computer games can actually increase the ecological validity or, at least, the lifelikeness of psychological research. This was one of the thematic benefits identified in the second symposium on "Computer Games in Psychological Research," organized for the 1999 Society for Computers in Psychology meeting.

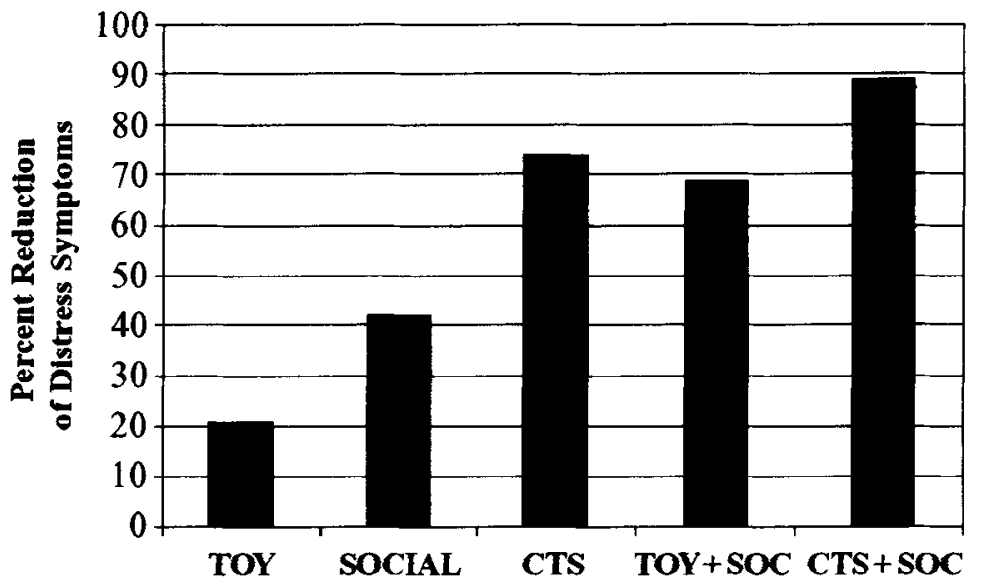

Figure 5. Effectiveness of different enrichment options in reducing distress behaviors (e.g., stereotypies, overgrooming, aggressive acts, or distress vocalizations) of rhesus monkeys. Toy refers to any manipulandum available to the monkeys (e.g., balls, puzzle boxes, or swings), and CTS refers to the game-like tasks of the computerized test system. In the social (soc) conditions, compatible pairs of monkeys were housed in the same cage. In all the other conditions, monkeys were singly housed. 
Several of the speakers in that symposium discussed gamebased research that brings aspects of real-world performance into the laboratory. This theme is illustrated by simulations such as those used to study driving (e.g., Gugerty \& Tirre, 2000) or air traffic control (e.g., Ackerman \& Cianciolo, 2000), virtual environments used to study spatial memory (e.g., Astur, 2001) or social behavior (e.g., Blascovich, Loomis, \& Beall, 2002), and computerized versions of educational tasks (e.g., Henderson, Klemes, \& Eshet, 2000; Klawe, 1999). These games provide new ways to ask old questions, ways that promise to combine with traditional laboratory tasks to converge on a new understanding of psychological processes and to generalize to everyday contexts with unsurpassed fidelity.

With advances in computer game hardware and software, there is no predicting what new developments may spawn the next generation of psychological research. That said, there remain ample opportunities to examine perception, attention, learning, memory, motivation, emotion, social behavior, problem solving, planning, strategy formation, and other psychological phenomena, using computer games and game-like tasks. Thus, the next time you catch a student or a colleague wasting a few moments playing computer games, consider that you might be witnessing the beginnings of a new research theme that is novel, innovative, productive, and-dare 1 say it-academic!

\section{REFERENCES}

Ackerman, P. L., \& Cianciolo, A. T. (2000). Cognitive, perceptualspeed, and psychomotor determinants of individual differences during skill acquisition. Journal of Experimental Psychology: Applied, 6, 259-290.

ALLAN, R. W. (1995). The matching game: Testing for the generality of the matching law. Behavior Research Methods, Instruments, \& Computers, 27, 206-210.

ARNOLD, H. J. (1976). Effects of performance feedback and extrinsic reward upon high intrinsic motivation. Organizational Behavior \& Human Decision Processes, 17, 275-288.

Arthur, W., Strong, M. H., Williamson, J. E., Jordan, J. A., SheBILSKE, W., \& REGIAN, W. (1995). Visual attention: Individual differences in training and predicting complex task performance. Acta Psychologica, 88, 3-23.

ASTUR, R. S. (2001). The role of the human hippocampus in a virtual Morris water maze task. Unpublished doctoral dissertation, University of New Mexico.

Blascovich, J. J., LoOmis, J., \& Beall, A. C. (2002). Immersive virtual environment technology as a methodological tool for social psychology. Psychological Inquiry, 13, 103-124.

Breland, K., \& Breland, M. (1961). Misbehavior of organisms. American Psychologist, 16, 681-684.

CASE, D. A. (1995). On trekking to operant frontiers. Behavior Research Methods, Instruments, \& Computers, 27, 211-216.

CoomBs, D. H. (1978). Is there a future for simulation and gaming research? Educational Communication \& Technology, 26, 99-106.

Donchin, E. (1995). Video games as research tools: The Space Fortress game. Behavior Research Methods, Instruments, \& Computers, 27, 217-223.

Filion, C. M., Washburn, D. A., \& Gulledge, J. P. (1996). Can monkeys respond to invisible displacements? Journal of Comparative Psychology, 110, 386-395.

GonZalez, F. A., \& CaTHCART, M. (1995). A procedure for studying strategy development in humans. Behavior Research Methods, Instruments, \& Computers, 27, 224-228.
GUGERTY, L. J., \& TIRRE, W. C. (2000). Individual differences in situation awareness. In M. R. Endsley \& D. J. Garland (Eds.), Situation awareness analysis and measurement (pp. 249-276). Hillsdale, $\mathrm{NJ}$ : Erlbaum.

Hanley, J., WALter, D. O., \& Rhodes, J. M. (1968). Chimpanzee petformance: Computer analysis of electroencephalograms. Nature, 220, 879-891.

Henderson, L., Klemes, J., \& Eshet, Y. (2000). Just playing a game? Education simulation software and cognitive outcomes. Journal of Educational Computing Research, 22, 105-129.

Hopkins, W. D., Washburn, D. A., \& Rumbaugh, D. M. (1990). Processing of forms stimuli presented unilaterally in humans, chimpanzees (Pan troglodytes), and monkeys (Macaca mulatta). Behavioral Neuroscience, 104, 577-584.

Isen, A. M., Shalker, T. E., Clark, M., \& Karp, L. (1978). Affect, accessibility of material in memory, and behavior: A cognitive loop? Journal of Personality \& Social Psychology, 36, 1-12.

Jones, M. B., Kennedy, R. S., \& BitTner, A. C. (1981a). A video game for performance testing. American Journal of Psychology, 94, 143-152.

Jones, M. B., KenNedy, R. S., \& BitTner, A. C. (1981b). Video games and convergence or divergence with practice (Rep. No. NBDL81R010). New Orleans: U.S. Naval Biodynamics Laboratory

Kennedy, R. S., Bittner, A. C., Harbeson, M. M., \& Jones, M. B. (1982). Television computer games: A "new look" in performance testing. Aviation, Space, \& Environmental Medicine, 53, 49-53.

Kennedy, R. S., Bittner, A. C., \& Jones, M. B. (1981). Video-game and conventional tracking. Perceptual \& Motor Skills, 53, 310.

KLAWE, M. (1999). Computer games, education and interfaces: The E-GEMS project. Proceedings of Graphics Interface '99. Kingston, ON.

LESGOLD, A. M. (1982). Computer games for the teaching of reading. Behavior Research Methods \& Instrumentation, 14, 224-226.

MALONE, T. W. (1980). What makes things fun to learn? A study of intrinsically motivating computer games. Unpublished doctoral dissertation, Stanford University.

Mane, A. M., \& Donchin, E. (1989). The Space Fortress game. Acta Psychologica, 7, 17-22.

MiCKEL, C. (1982). Innovative projects earning psychologists spots on hospital health care teams. American Psychologist, 37, 1350-1354.

MouLDS, E. E. (1979). Selected physiological measures of arousal of high-and low-trait anxiety females during competition. Unpublished doctoral dissertation, Louisiana State University and A\&M College.

PorTer, D. B. (1995). Computer games: Paradigms of opportunity. Behavior Research Methods, Instruments, \& Computers, 27, 229-234.

RANSDELL, S. (2002). Teaching psychology as a laboratory science in the age of the Internet. Behavior Research Methods, Instruments, \& Computers, 34, 145-150.

ReISMAN, S. (1972). Dominoes: A computer simulation of cognitive processes. Simulation \& Games, 3, 155-164.

Romski, M. A., \& SEvcIK, M. A. (1996). Breaking the speech barrier: Language development through augmented means. Baltimore: Brookes.

Rumbaugh, D. M. (1977). Language learning by a chimpanzee: The LANA project. New York: Academic Press.

Rumbaugh, D. M., Richardson, W. K., Washburn, D. A., SavageRuMBAUGH, E. S., \& HoPKINS, W. D. (1989). Rhesus monkeys (Macaca mulatta), video tasks, and implications for stimulus-response spatial contiguity. Journal of Comparative Psychology, 103, 32-38.

Savage-Rumbaugh, E. S. (1986). Ape language: From conditioned response to symbol. New York: Columbia University Press.

SCHEIBE, K. E., \& ERWIN, M. (1979). The computer as alter. Journal of Social Psychology, 108, 103-109.

Shebilske, W. L., Goettl, B. P., Corrington, K., \& Day, E. A. (1999). Interlesson spacing and task-related processing during complex skill acquisition. Journal of Experimental Psychology: Applied, $5,413-437$

Smith, J. D., Shields, W. E., Allendoerfer, K. R., \& Washburn, D. A. (1998). Memory monitoring by animals and humans. Journal of Experimental Psychology: General, 127, 227-250.

WAKSMAN, A. (1974). The introduction of programming to perspective authors of CAI programs. Educational Technology, 14, 33-34. 
WASHBURN, D. A. (1993). The stimulus movement effect: Allocation of attention or artifact? Journal of Experimental Psychology: Animal Behavior Processes, 19, 1-10.

WASHBURN, D. A. (1994). Stroop-like effects for monkeys and humans: Processing speed or strength of association? Psychological Science, 5, 375-379

WASHBURN, D. A., \& Astur, R. S. (1998). Comparative investigations of visuospatial memory: Rehearsal in the sketchpad? Memory \& Cognition, 26, 277-286.

WAShburn, D. A., \& Gulledge, J. P. (1995). Game-like tasks for comparative research: Leveling the playing field. Behavior Research Methods, Instruments, \& Computers, 27, 235-238.

Washburn, D. A., \& Gulledge, J. P. (in press). Comparative assessment of visuospatial memory: I. The concentration task. International Journal of Comparative Psychology.

Washburn, D. A., Hopkins, W. D., \& Rumbaugh, D. M. (1989). Automation of learning-set testing: The video-task paradigm. Behavior Research Methods, Instruments, \& Computers, 21, 281-284.

Washburn D. A., Putney, R. T., \& Henderson, B. (1995). Harder to do, easier to learn: Manipulations of attention in training. Proceedings of the 39th meeting of the Human Factors and Ergonomics Society (Abstract), 963.

WAShBURN, D. A., \& RABY, P. R. (2003). Game-like interactivity promotes learning in on-line instruction. Manuscript submitted for publication.

Washburn, D. A., \& Rumbaugh, D. M. (1991a). Ordinal judgments of
Arabic symbols by macaques (Macaca mulatta). Psychological Science, 2, 190-193.

Washburn, D. A., \& Rumbaugh, D. M. (1991b). Rhesus monkey (Macaca mulatta) complex learning skills reassessed. International Journal of Primatology, 12, 377-388.

WashbuRn, D. A., \& RUMBaUGH, D. M. (1992). Investigations of thesus monkey video-task performance: Evidence for enrichment. Contemporary Topics in Laboratory Animal Science, 31, 6-10.

Wittgenstein, L. (1953). Philosophical investigations (G. E. M. Anscombe, Trans.). New York: MacMillan.

Yermakova, I. V. (1982). An automatized logical-play system for use in psychological experimentation. Voprosy Psychologii, 2, 125-127.

\section{NOTE}

1. I should note that I celebrated this 20-year anniversary of my first computer purchase by connecting that VIC-20 to that same old television, turning them on, loading some of that software, and playing those old games. That computer still worked like new after 20 years, something that cannot be said for some of my newer, more powerful computers after even a year or two!

(Manuscript received January 27, 2003; accepted for publication February 2, 2003.) 